\title{
High-density genetic map construction and quantitative trait loci analysis of the stony hard phenotype in peach based on restriction-site associated DNA sequencing
}

Shaolei Guo 1,2,3, Shahid lqbal ${ }^{1}$, Ruijuan Ma ${ }^{2,3}$, Juan Song ${ }^{2,3}$, Mingliang $\mathrm{Yu}^{2,3^{*}}$ and Zhihong Gao ${ }^{1 *}$

\begin{abstract}
Background: Peach (Prunus persica) is an important fruit crop that generally softens rapidly after harvest resulting in a short shelf-life. By contrast, stony hard (SH) peach fruit does not soften and hardly produces ethylene. To explore the candidate genes responsible for the SH phenotype, a high-density genetic map was constructed by restriction-site associated DNA sequencing technology.

Results: In the present study, the linkage map consisted of 1310 single nucleotide polymorphism markers, spanning $454.2 \mathrm{cM}$, with an average marker distance of $0.347 \mathrm{cM}$. The single nucleotide polymorphisms were able to anchor eight linkage groups to their corresponding chromosomes. Based on this high-density integrated peach linkage map and two years of fruit phenotyping, two potential quantitative trait loci for the $\mathrm{SH}$ trait were identified and positioned on the genetic map. Additionally, Prupe.6G150900.1, a key gene in abscisic acid (ABA) biosynthesis, displayed a differential expression profile identical to the ABA accumulation pattern: mRNA transcripts were maintained at a high level during storage of $\mathrm{SH}$ peaches but occurred at low levels in melting fruit.

Conclusion: Thus Prupe.6G150900.1 might play a crucial role in the SH phenotype of peach in which ABA negatively regulates ethylene production. Also, this high-density linkage map of peach will contribute to the mapping of important fruit traits and quantitative trait loci identification.
\end{abstract}

Keywords: Peach, Stony hard, Restriction-site associated DNA sequencing, Genetic map, Quantitative trait loci, Gene expression

\section{Background}

Peach [Prunus persica (L.) Batsch] is a typical climacteric fruit, and it generally softens rapidly after harvest, resulting in a short shelf-life that unfavorably affects its market value $[1,2]$. Therefore, peach fruit texture is an important quality in the breeding of fresh market varieties.

To date, peach cultivars have been classified into three flesh texture types, melting (M), no-melting (NM) and stony hard $(\mathrm{SH})$ based on the characteristics of fruit firmness and texture changes during peach ripening and

\footnotetext{
* Correspondence: gaozhihong@njau.edu.cn; mly1008@aliyun.com ${ }^{1}$ College of Horticulture, Nanjing Agricultural University, Nanjing 210095, China

${ }^{2}$ Institute of Pomology, Jiangsu Academy of Agricultural Sciences, Nanjing 210014, China

Full list of author information is available at the end of the article
}

softening [3-5]. Generally, M fruit are characterized by their prominent softening after harvest, NM fruits are characterized by slow softening at the later stages of ripening and never melt, while the SH type does not produce ethylene and barely softens after harvest (both on- and off-tree) $[3,4,6]$. A genetic analysis indicated that the $\mathrm{SH}$ genotype is controlled by a single recessive gene [5] and is epistatic to the locus [4].

In general, the softening of climacteric fruit, is related to endo-polygalacturonase enzyme activity, and is induced by ethylene [7-9]. A low level of ethylene production may contribute to the suppression of fruit softening in $\mathrm{SH}$ peach cultivars, and this depends on the suppressed transcription of PpACS1 [10]. The suppression of PpACS1 is caused by low indole-3-acetic acid concentrations in $\mathrm{SH}$ 
peaches [11]. PpYUC11 may play an essential role in auxin biosynthesis during peach fruit ripening and is a candidate gene for controlling the SH phenotype in peach [6]. However, Dong et al. [12] showed that ABI4-mediated the transcriptional repression of the ethylene biosynthesis genes ACS4 and ACS8 in Arabidopsis. Li et al. [13] suggested that in ethylene over-producer mutants, abscisic acid (ABA) treatments suppress ACS5 transcripts levels and the ethylene content, indicating that ethylene production is determined by various metabolic pathways.

The advancements in next-generation sequencing (NGS) technologies coupled with continually reducing costs, offers unprecedented conditions for genome-wide marker development and genotyping by sequencing [14]. Restriction-site associated DNA sequencing (RAD-seq) is a foremost NGS technology for high-throughput genotyping [15], in which a reduced representation of the genome produced by the DNA flanking specific a restriction enzyme is sequenced, and the reduced genome is bound to an adapter containing multiplex identifiers to form reduced-representation libraries [15-17]. To date, high-density genetic maps of many species, including eggplant [18], ryegrass [19], barley [20], grape [16], sesame [17], pear [21], apple [22] and cowpea [15], have been constructed using the RAD-seq method. However, RAD-seq technology is barely applied in peach.

To clarify the mechanism responsible for the SH phenotype and improve fruit quality, especially texture by peach breeding, further research is needed. Currently, genetic maps constructed with molecular markers have been constructed to detect the genomic loci or genes related to the traits of interest may provide efficient methods [23]. To explore the candidate gene which controls the SH phenotype, the phenotype-related quantitative trait loci (QTLs) were identified through a high-density single nucleotide polymorphism (SNP) linkage map of the peach genome with the RAD-seq technology and a family of $103 \mathrm{~F}_{1}$ lines phenotypic identification.

\section{Results}

\section{Phenotypic identification}

In the present study, we identified $42 \mathrm{SH}$ and $49 \mathrm{M}$ fruit trees based on the ethylene production phenotype during storage at room temperature in 2016, and individuals $5,37,39,42,63,67,69,70,71,88,102$ and 103 were unidentified due to less fruits (Fig. 1 and Additional file 1a). In addition, all $42 \mathrm{SH}$ fruit tree and 12 unidentified trees were identified according to ethylene production in 2017. The $42 \mathrm{SH}$ fruit trees identified in 2016 also exhibited the SH phenotype in 2017 (hardly synthesizing ethylene), and trees 5, 37, 70, 88 and 103 were identified as $\mathrm{SH}$ phenotype in 2017 according to ethylene production. Trees 63, 67 and 102 were identified as M phenotype, while trees 39, 42, 69 and 71 remained unidentified owing to less fruits in 2017 (Fig. 2). Furthermore, 45 fruit trees were identified as $\mathrm{SH}$ phenotype and 47 fruit trees as M phenotype based on the phenotype of firmness in 2017, while 11 fruit trees remained unidentified $(39,42,57,59$, 69, 71, 73, 76, 78, 93 and 95) owning to less fruits (Fig. 3 and Additional file 1b). The segregation of the $\mathrm{SH}$ phenotype in the $F_{1}$ family (103) of the cross between 'Yumyeoung' (YM) (female) and 'Hujingmilu' (HJML) (male) presented 1:1 ratio (Table 1) based on both ethylene production and fruit firmness, which indicated that the SH phenotype may be controlled by a single recessive gene. Finally, the phenotypic identifications based on ethylene production in 2016 and 2017 were used for a QTL analysis (Additional file 1c).

\section{ABA content determination}

There is no significant difference in the early stage of storage between the $\mathrm{SH}$ fruit 'YM' and the M fruit of 'HJML' of the ABA content, but significantly higher in 'YM' cultivar than that in 'HJML' cultivar during the later storage period (Fig. 4).

\section{RAD-seq and linkage map construction}

After filtering, there were 8550.55 million clean reads, consisting of $\sim 85.51 \mathrm{~Gb}$, that were used to generate RAD tags (Additional file 2). Thus, the reads ensured that more than 91 and $96 \%$ of the nucleotides had a quality values above Q30 (equal to a 0.1\% sequencing error) and Q20 (equal to a $1 \%$ sequencing error), respectively (Additional file 2). The GC content for both parents and offspring were $\sim 38.7 \%$. A total of 6150 SNP markers were used for linkage map construction (Additional file 3). As a result, 1310 markers were selected and mapped onto eight different linkage groups (LGs), covering $454.2 \mathrm{cM}$ of the peach genome and having an average distance of $0.347 \mathrm{cM}$ between adjacent markers (Table 2 and Fig. 5). The length of individual LGs ranged from $36.9 \mathrm{cM}$ (LG7) to $83.0 \mathrm{cM}$ (LG3), with inter-locus distances of between 0.18 (LG7) and $0.809 \mathrm{cM}$ (LG5). LG1 was the densest, having 212 SNP loci, while LG5 had the least number of SNP loci (55). A linkage map including genetic distances and loci names, associated with SNP marker positions in different LGs is presented in Fig. 5.

\section{SNP and QTL analyses}

Overall, 51,253 polymorphic SNPs were identified between the two parental genotypes and those of their individual offspring (Additional file 4). To characterize the SNPs in peach, we determined the percentages of different SNP types. Among these SNPs, the dominant types were transitions, and the $\mathrm{A} / \mathrm{G}$ and $\mathrm{C} / \mathrm{T}$ types represented to 32.1 and $31.9 \%$ of the SNPs, respectively. The other four SNP types were the trans-versions $\mathrm{A} / \mathrm{T}$, $\mathrm{A} / \mathrm{C}, \mathrm{G} / \mathrm{T}$, and $\mathrm{G} / \mathrm{C}$. Their proportions varied from 6.9 


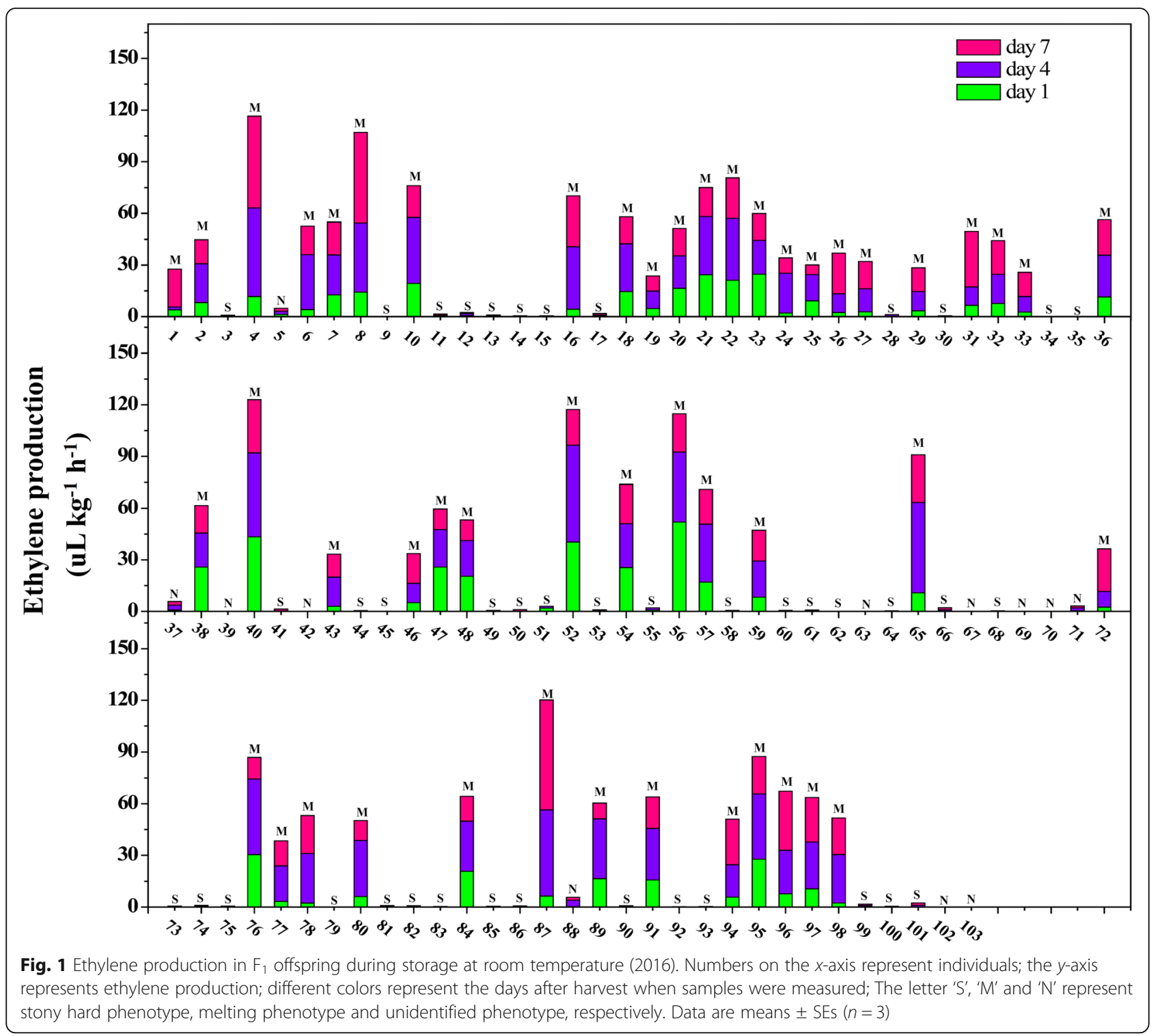

to $10.0 \%$, accounting for $36 \%$ of all SNPs (Table 3). All of the SNP types present in each individual are summarized in Additional file 5. A High-Density Genetic Map constructed using two years of fruit phenotyping was employed to identify SH phenotype-linked QTL in peach. Two SH phenotypic-related QTLs were found in one linkage group (LG6) using the ICIM-ADD method (Table 4).

\section{Functional analysis of candidate genes}

A total of 249 discrete genes were obtained from the two QTL regions (Additional file 6). Of these 80 genes were identified in the Gene Ontology (GO) database and, could be categorized into 28 functional groups, including 14 in biological processes, 9 in cellular components and 5 in molecular functions. The distribution of these eighty genes ranged from 1 (in growth) to 48 (in metabolic processes) in the different functional groups. Most of the genes were involved in the cellular process (39), metabolic process (48), cell (42), cell part (42), binding (46) and catalytic activity (39) (Fig. 6). The distribution of the 80 genes in GO Database is list in Additional file 6. Of the 249 candidate genes, 84 were identified in the Kyoto Encyclopedia of Genes and Genomes (KEGG) pathway database, and they were associated with 19 pathways. The pathway with the highest enrichment factor was carotenoid biosynthesis, and a Q-value of $<0.05$ was found for plant hormone signal transduction, carotenoid biosynthesis, phenylpropanoid biosynthesis, cyanoamino acid metabolism, starch and sucrose metabolism and regulation of autophagy (Additional file 7). These pathways may be significantly involve in determining the $\mathrm{SH}$ phenotype, and the 84 genes identified in the KEGG pathway database are listed in Additional file 6. 


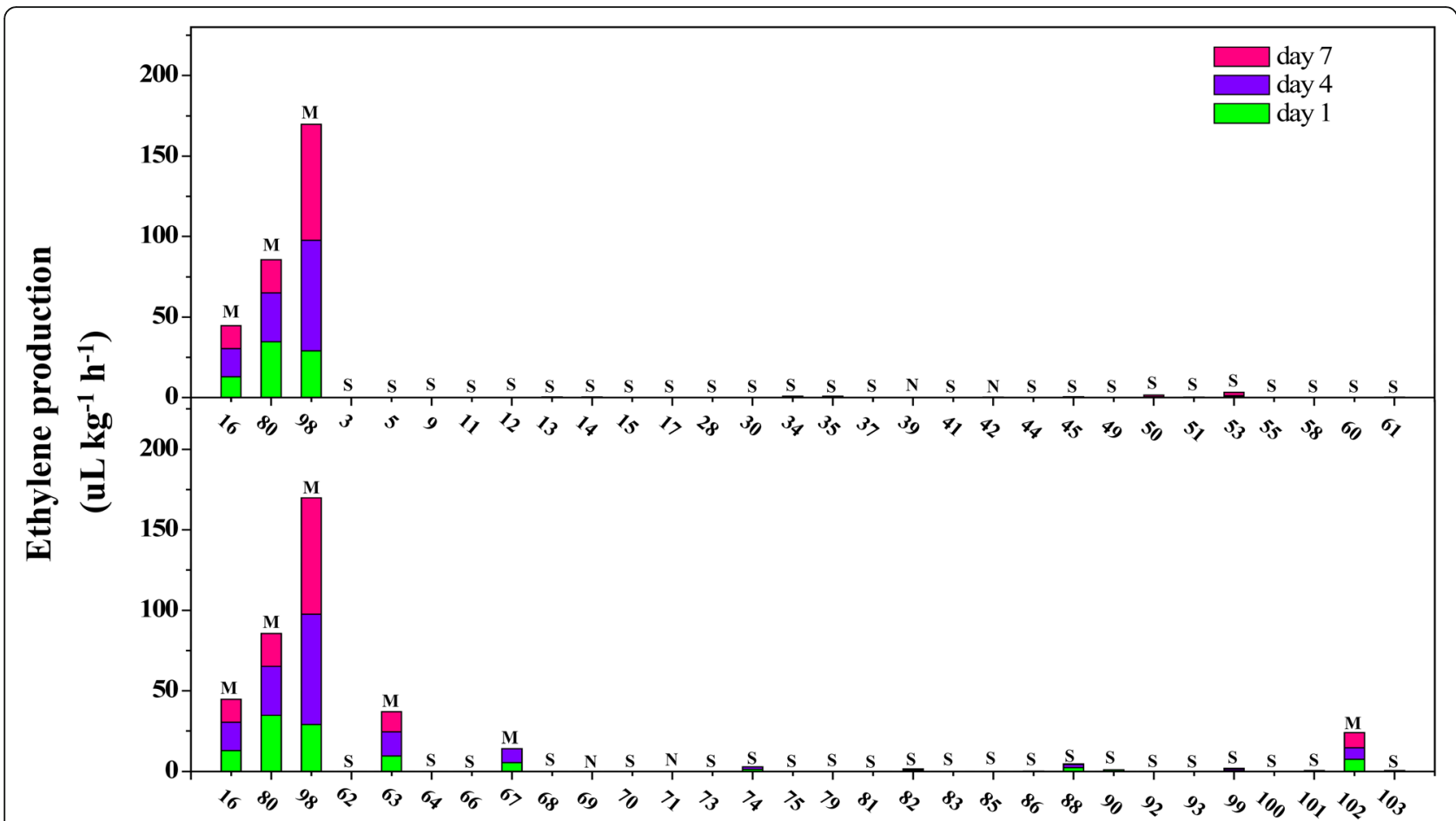

Fig. 2 Ethylene production in $F_{1}$ offspring during storage at room temperature (2017). Numbers on the $x$-axis represent individuals; the $y$-axis represents ethylene production; different colors represent the days after harvest when samples were measured; The letter ' $S$ ', ' $M$ ' and ' $N$ ' represent stony hard phenotype, melting phenotype and unidentified phenotype, respectively. Individuals of 16,80 and 98 as a contrast. Data are means SEs $(n=3)$

\section{Expression analysis using real-time quantitative PCR (RT-} qPCR)

249 genes were aligned to the Genome Database for Rosaceae (GDR) (https://www.rosaceae.org/node/1) to identify the candidate genes. In total, 11 candidate genes (with $P$-value $<0.05$ in pathway) in peach cultivars with distinct softening characteristics were analyzed using RT-qPCR (Fig. 7). In the present study, the expression of Prupe.6G150900.1 was significantly higher in SH fruit ('YM') than that in $M$ fruit ('HJML') during storage (Fig. 7), the same phenomenon occurred in other $\mathrm{M}$ ('XH8') and $\mathrm{SH}$ ('XC') fruit, which indicated that Prupe.6G150900.1 was expressed higher in $\mathrm{SH}$ fruit than in $\mathrm{M}$ fruit. The profiles were similar to those of the ABA content in 'HJML' and 'YM'. Likewise, Prupe.6G147600.1 was expressed significantly higher in 'YM' than in 'HJML' fruit, but in 'XH8' and ' $\mathrm{XC}$ ' expressed no significant diversity during later storage stage. Prupe.6G156500.1 was expressed significantly higher in 'HJM'L fruit than in 'YM' fruit (Fig. 7) and also expressed no significant diversity in ' $\mathrm{XH8}$ ' and ' $\mathrm{XC}$ ' cultivars. The other genes in Fig. 7 showed no significant diversity between $\mathrm{SH}$ and M-type cultivars.

\section{Discussion}

SH inheritance in peach

$\mathrm{SH}$ phenotype is projected to be used as a genetic resource for breeding to meet fresh market requirements [24].
Additionally, identifying the mechanisms responsible for the $\mathrm{SH}$ phenotype is of great importance. The segregation of the $\mathrm{SH}$ phenotype in the $\mathrm{F}_{1}$ family (103) of the cross between 'YM' and 'HJML' in our study was consistent with Mendelian inheritance (1,1ratio). Which suggested that the $\mathrm{SH}$ trait is controlled by a single recessive gene. These results are consistent with Yoshida's research [5].

\section{Construction of a high-density genetic map for peach}

Generally, molecular markers and genetic maps are widely used in the genetic mapping of important traits in crops [25]. RAD-seq technology has been employed as an efficient tool for high-density genetic mapping and QTL analyses with the capacity to discover larger numbers of markers in any organism (with or without reference genomes) [15, 26-29]. To date, no RAD-seq-based SNP discover technique has been reported in peach. In the present study, a high-density SNP linkage map in peach was constructed and characterized using the RAD-seq method. In 1994, Chaparro et al. [30] constructed the first linkage map of peach. With the development of molecular marker technology, RFLP, RAPD, AFLP and SSR markers [31-36], especially SSR were widely used to construct linkage maps in peach. Compared with microsatellites and other markers, SNPs are efficient tools for linkage mapping that can be genotyped on a more abundant and much larger scale [21, 37]. The 'Texas' $\times$ 'Earlygold' genetic map is 


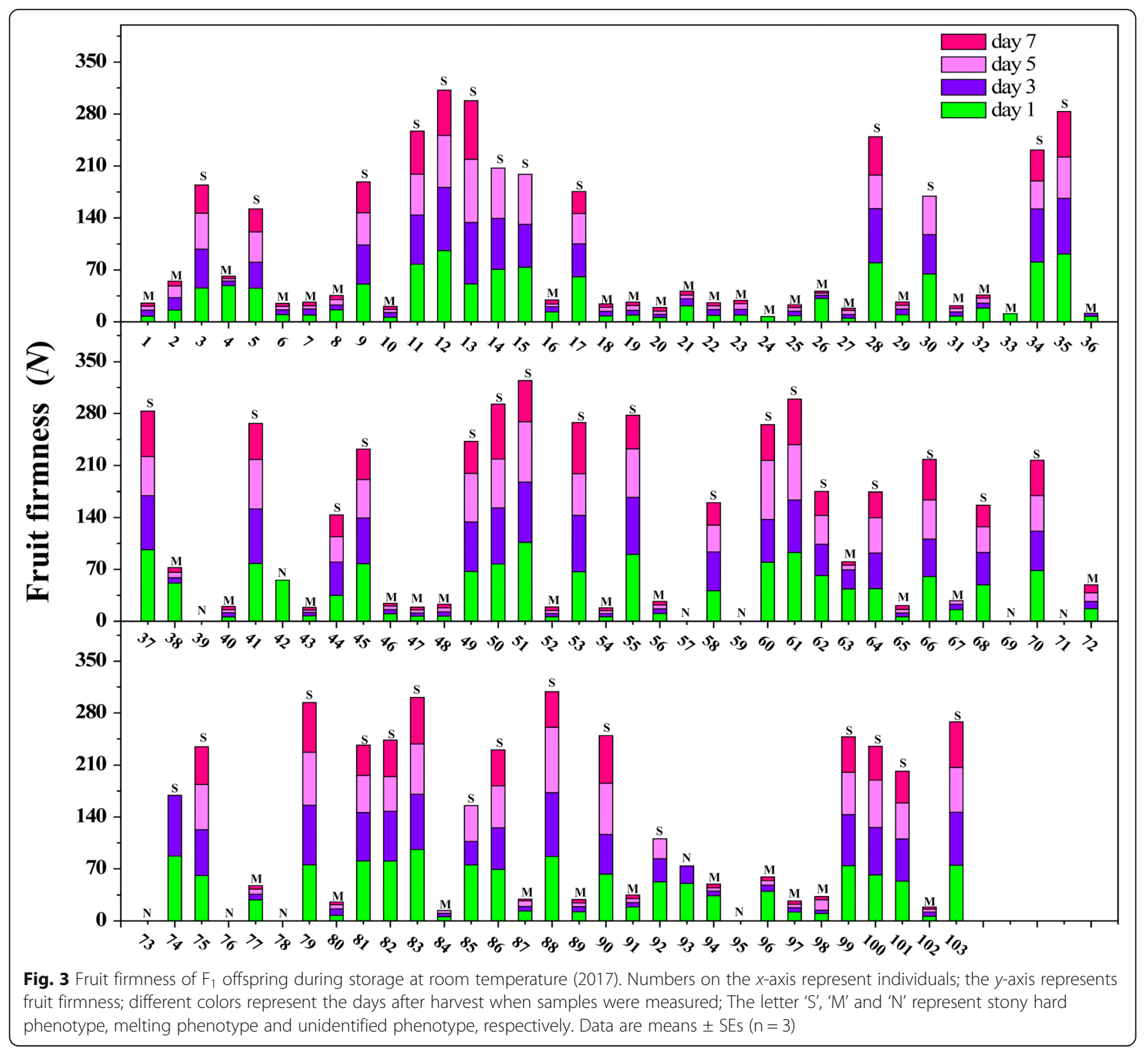

considered the reference map for Prunus, having 562 markers and, covering $517 \mathrm{cM}$ of the peach genome with an average distance of $0.92 \mathrm{cM}$ between adjacent markers (http://www.rosaceae.org/maps) [38]. Recently, two high-density linkage maps were constructed: the Pop-DF map, covering $422 \mathrm{cM}$ of the peach genome and including 1037 SNP markers (0.407 cM/SNP locus), and the Pop-DG

Table 1 Segregation of the SH phenotype in $F_{1}$ population (103) of the cross between 'YM' and 'HJML'

\begin{tabular}{lllllll}
\hline Year & based trait & $\mathrm{SH}^{\mathrm{a}}$ & $\mathrm{M}^{\mathrm{b}}$ & Unidentified & Expected rate & $\mathrm{X}^{2 \mathrm{c}}$ \\
\hline 2016 & ethylene & 42 & 49 & 12 & $1: 1$ & 1.650 \\
2017 & firmness & 45 & 47 & 11 & $1: 1$ & 1.010 \\
\hline
\end{tabular}

${ }^{\mathrm{a}} \mathrm{SH}$, stony hard

${ }^{\mathrm{b}} \mathrm{M}$, melting

${ }^{c} X^{2}$ represents the chi-squared value with the $P$-value set at 0.05 map covering $369 \mathrm{cM}$ and including $738 \mathrm{SNPs}(0.5 \mathrm{cM} /$ SNP locus) [39]. The map size reported here is $454.2 \mathrm{cM}$, which is shorter than the previously published maps of $562.3 \mathrm{cM}$ [35] and $1061.8 \mathrm{cM}$ [40] in peach. This might be the result of the limited LGs linkage groups or segregation distortion markers present in our map. The same phenomenon occurred for sesame [17]. This was the first mapping family reported in peach. Additionally, this genetic map had the highest marker density, and fewer distortion markers compared with other published genetic maps in peach $[35,38,41]$. The inter-marker distance of $0.347 \mathrm{cM}$ suggested that it would be favorable for locating sequence scaffolds on the physical peach genome sequence map. Because the whole-genome sequence of peach has been released [42], it could be beneficial for obtaining genes near each marker. 


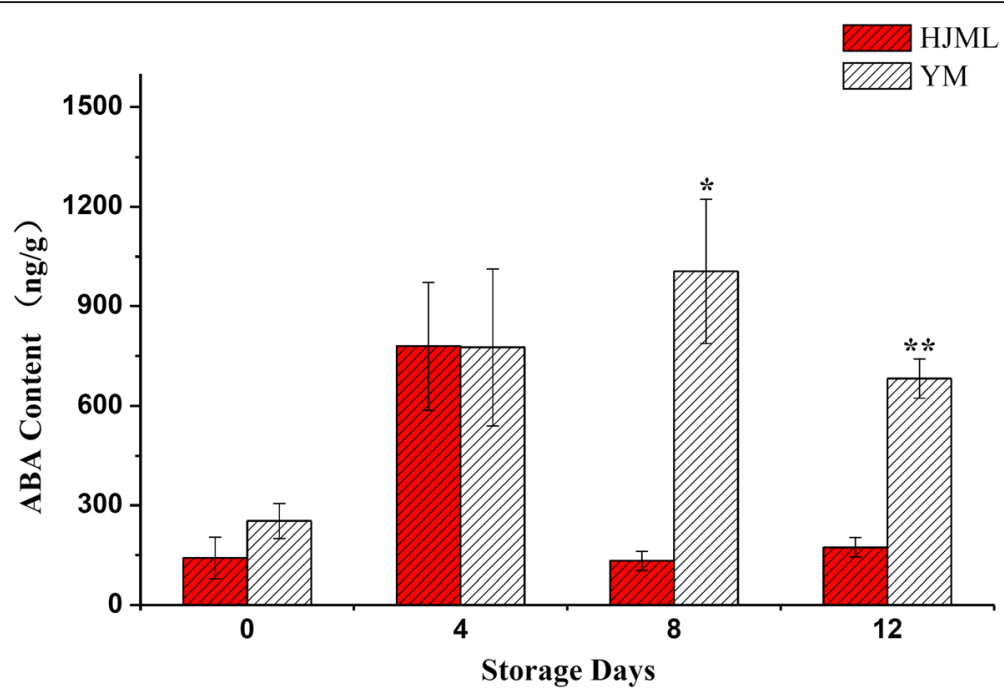

Fig. 4 ABA contents of 'HJML' and 'YM' during storage at room temperature. The $x$-axis represents the storage days after harvest; the $y$-axis represents the ABA content. Data are means \pm SEs $(n=3)$. Significant differences $(p<0.05)$ between means are indicated by the symbol ${ }^{* \prime}$ and significant differences $(p<0.01)$ between means are indicated by the symbol '**'

\section{Identification of QTLs related to the SH phenotype in peach}

Mapping QTLs in peach is challenging because the peach plant is highly heterozygous with a long growth and breeding cycle. Mapping and QTL have been performed using $F_{1}[39,41,43] F_{2}$ and $B C 1$ families, as shown at http://www.rosaceae.org/maps. Fruit quality is considered the primary significant selection criteria by peach breeders [44] and, mainly includes color, flavor and texture. Shen et al. [35] mapped the Dominant Blood-Flesh locus, which may control the blood-flesh phenotype of 'Wu Yue Xian' peach to the top of LG5. Aromatic and other volatile compounds were mapped onto the Prunus reference map using gas chromatography-mass spectrometry [45, 46]. The NM flesh trait locus may be located in the central region of LG4 with recessive alleles determining the characteristics [47]. The activity of an endo-polygalacturonase

Table 2 Distribution of mapped markers among eight linkage groups in peach

\begin{tabular}{llll}
\hline Linkage group & Number of markers & Length $(\mathrm{cM})$ & Average distance $(\mathrm{cM})$ \\
\hline LG1 & 212 & 41.9 & 0.198 \\
LG2 & 129 & 65.3 & 0.506 \\
LG3 & 195 & 83.0 & 0.426 \\
LG4 & 119 & 55.7 & 0.468 \\
LG5 & 55 & 44.5 & 0.809 \\
LG6 & 186 & 74.2 & 0.399 \\
LG7 & 205 & 36.9 & 0.180 \\
LG8 & 209 & 52.7 & 0.252 \\
Total & 1310 & 454.2 & \\
Average & 163.75 & 56.775 & 0.347 \\
\hline
\end{tabular}

gene was associated with $M$ flesh [48]. Recently, Serra et al. [49] identified the qP-MD5 QTL as a key factor for slow $\mathrm{M}$ flesh, and qP-MD6 may modulate the maturity date trait. With the development of sequencing and SNP-genotyping platforms, high-resolution linkage maps have been successfully used to locate qualitative and quantitative traits $[21,50]$. A total of 32 potential QTLs for 11 traits (5 quantitative and 6 qualitative traits), including length of pedicel, single fruit weight, soluble solid content, transverse diameter, vertical diameter, calyx status, flesh color juice content, number of seeds, skin color, and skin smooth, were identified and positioned in pear [21]. As an important texture type, the $\mathrm{SH}$ phenotype is of importance in peach $[4,6,10,11]$. In this study, the pathway with the highest enrichment factor was carotenoid biosynthesis and plant hormone signal transduction, these indicated that the $\mathrm{SH}$ phenotype may much correlation with ABA, and the crosstalk of ethylene and ABA is important for multiple physiological processes [51-53]. These will be of great beneficial in clarifying the mechanism responsible for the SH phenotype.

\section{Identification and expression analyses of candidate genes} Three genes (Prupe.6G150900.1, Prupe.6G147600.1 and Prupe.6G156500.1) were identified as good candidates for controlling the SH trait. Prupe.6G150900.1 was annotated as encoding abscisic-aldehyde oxidase 3, which was thought to catalyze the oxidation of the abscisic aldehyde reaction in the last step of ABA biosynthesis [54]. The expression of Prupe.6G150900.1 in the SH-type cultivar ('YM') was significantly higher than that in the M-type cultivar ('HJML') during storage. The same expression phenomenon also occurred in the ' $\mathrm{XC}$ ' $(\mathrm{SH})$ and ' $\mathrm{XH} 8$ ' (M) 


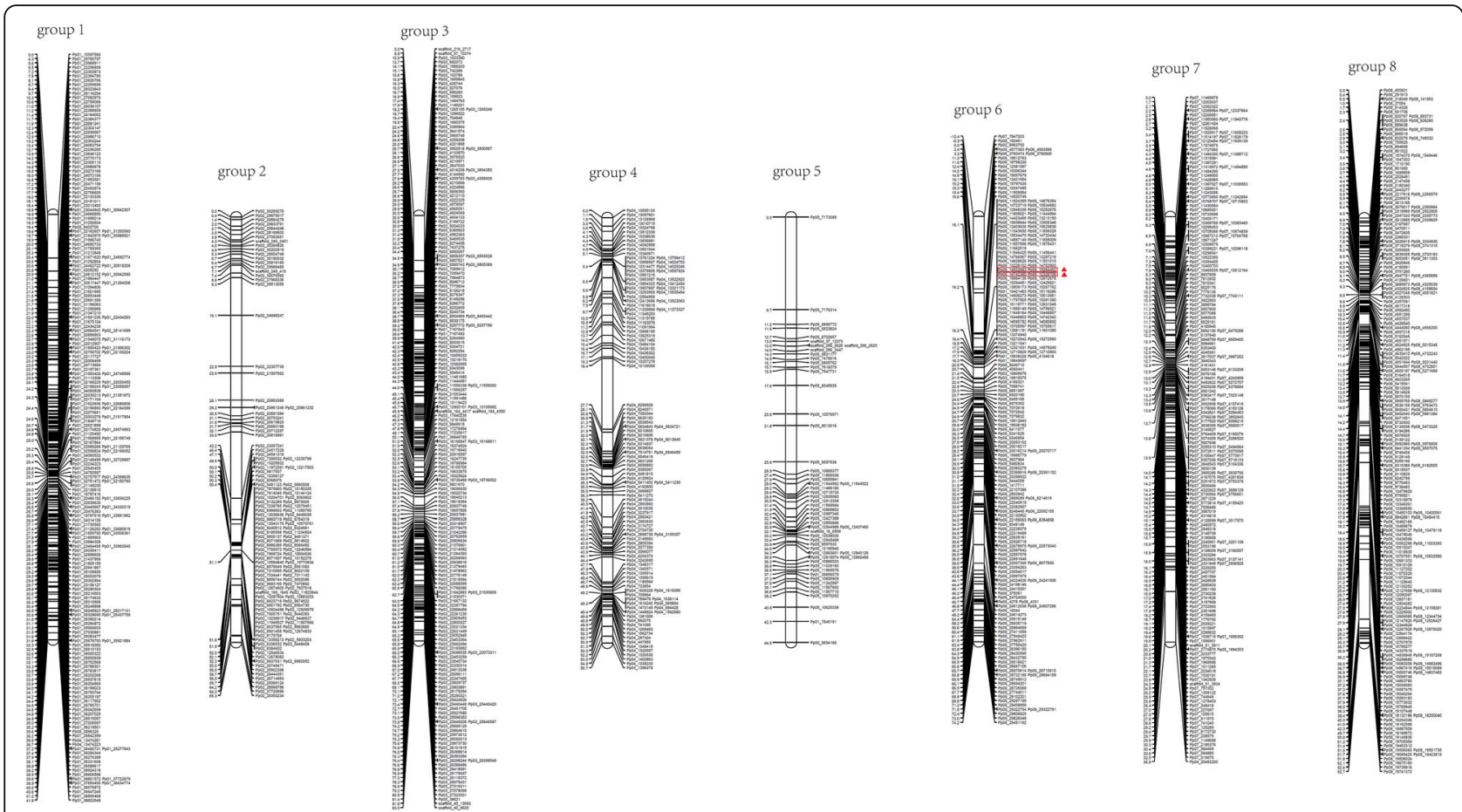

Fig. 5 Integrated linkage groups 1 to 8 for 'YM' $X^{\prime} H J M L$ '. Marker names are shown to the right of each group, and map distances (in $\mathrm{CM}$ ) are shown on the left. Red symbols represent the position of QTLS

cultivars. Furthermore, the ABA content in the SH-type cultivar ('YM') was significant high than in M-type cultivar ('HJML'). Thus the SH phenotype may have a close relationship with ABA. Multiple physiological processes are determined by the crosstalk between ABA and ethylene [51-53]. Particularly, the induction of ethylene biosynthesis can be prevented by ABA treatments [53, 55, 56]. Recent research suggested that $A B A$ negatively regulates ethylene production through the ABI4-mediated transcriptional repression of the ethylene biosynthesis genes ACS4 and ACS8 in Arabidopsis [12]. This indicates that Prupe.6G150900.1 may be an important factor in the inhibition of ethylene production through ABA. In addition Prupe.6G147600.1 was annotate as being related to the transcription factor YABBY, and Prupe.6G156500.1 was

Table 3 Statistics of all SNP types in the parent plants and their offspring

\begin{tabular}{lll}
\hline SNP types & Numbers & Ratio (\%) \\
\hline $\mathrm{A} / \mathrm{T}$ & 274,225 & 10.0 \\
$\mathrm{~A} / \mathrm{G}$ & 879,057 & 32.1 \\
$\mathrm{~A} / \mathrm{C}$ & 256,293 & 9.4 \\
$\mathrm{G} / \mathrm{T}$ & 265,966 & 9.7 \\
$\mathrm{G} / \mathrm{C}$ & 188,305 & 6.9 \\
$\mathrm{C} / \mathrm{T}$ & 874,086 & 31.9 \\
Total SNP numbers & $273,793,2$ & \\
\hline
\end{tabular}

annotate as encoding beta-glucosidase (EC3.2.1.21) an important hydrolase that may be related to the softening of peach fruit. In $M$ and $N M$ fruit cultivars, the endo-polygalacturonase activity during peach fruit ripening is responsible for the difference in softening $[8,9]$. Ethylene treatment resulted in $\mathrm{SH}$ type peach fruit softening rapidly and increasing endo-polygalacturonase enzyme activity and PpPG mRNA expression [57, 58]. And Prupe.6G156500.1 may related to the fruit softening as endo-polygalacturonase for the higher expression in $M$ cultivars and lower expression in $\mathrm{SH}$ cultivars. Further studies are needed to reveal the candidate genes' function in peach.

\section{Conclusion}

The use of high-density genetic map will be beneficial for mapping important fruit traits and for QTL identification in peach. Prupe.6G150900.1 may be an important factor involved in the inhibition of the ethylene production through $\mathrm{ABA}$ and might be an important candidate

Table 4 Analysis of SH phenotypic-related QTLS in peach

\begin{tabular}{llllll}
\hline Trait name & Group & Left marker & Right marker & LOD $^{\text {a }}$ & PVE(\%) \\
\hline SH & 6 & Pp06_14932683 & Pp06_15264452 & 9.2038 & $44.19 \%$ \\
SH & 6 & Pp06_14742390 & Pp06_12326708 & 2.5097 & $42.29 \%$ \\
\hline
\end{tabular}

aLOD, likelihood of odds

${ }^{\mathrm{b}} \mathrm{PVE}$, phenotypic variation explained 


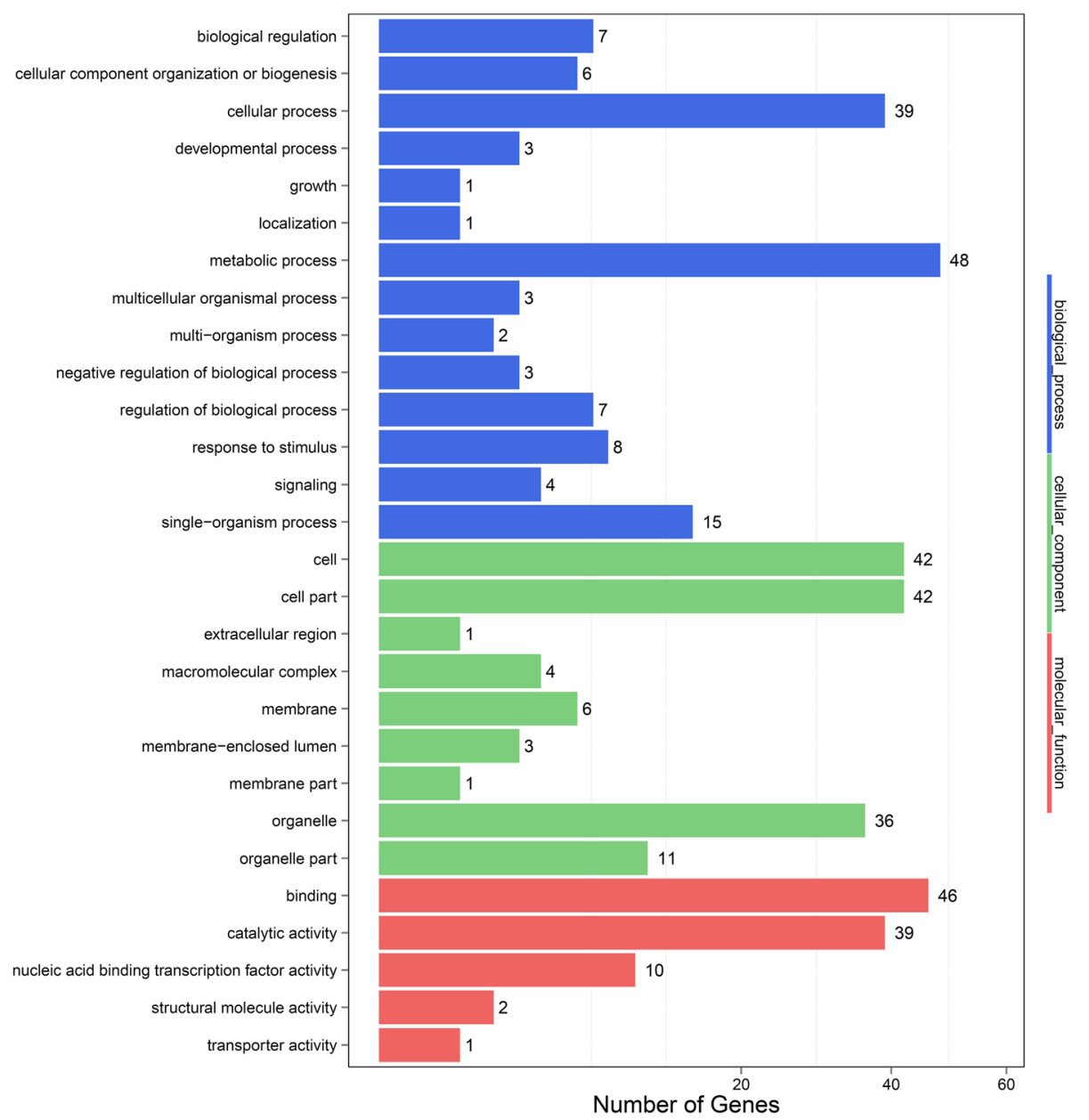

Fig. 6 Histogram showing the gene ontology functional enrichment of differentially expressed genes. Different colors represent distinct functional groups

gene for controlling the $\mathrm{SH}$ phenotype. These results will be useful for further analyses of SH phenotype.

\section{Methods}

\section{Materials and DNA extraction}

The two parents showed distinct softening characteristics, including fruit firmness and ethylene production. 'YM' and 'HJML' have significantly different texture phenotypes: 'YM' is $\mathrm{SH}$, maintaining fruit firmness and hardly synthesizing ethylene during storage at room temperature, and 'HJML' is M, rapidly softening and exhibiting an ethylene production peak during storage at room temperature [59]. The sample family consisted of $103 \mathrm{~F}_{1}$ progeny from a cross between two peach cultivars: the SH-type cultivar 'YM' and the M-type cultivar 'HJML'. The family was hybridized in 2008, These plants were grown at the experimental peach orchard in Nanjing, Jiangsu, China. Young leaves (first few leaves of the apex) were collected and immediately stored in liquid nitrogen and transferred to a $80{ }^{\circ} \mathrm{C}$ freezer in the laboratory. A sample from each individual was ground in liquid nitrogen and total genomic DNA was extracted using a Plant Genomic DNA Kit (TIANGEN, Beijing, China). A 1\% agarose gels and a spectrophotometer (Qubit 2.0 Fluorometer, Invitrogen) were used to determine the genomic DNA's integrity and quality, respectively.

\section{Detection of ethylene production and fruit firmness}

Ethylene production was measured by gas chromatography (Agilent 7890A, CA, USA) according to the method followed by Guo et al. [59] in 2016 and 2017, and fruit flesh firmness was measured using the TA-XT. Plus Texture Analyser (Stable Micro Systems Ltd., Godalming, Surrey, UK) according to the method of Guo et al. [59] in 2017. All fruit samples reached commercial maturity, had no diseases and mechanical damage with uniform maturity were randomly collected. And the fruits were stored in a room at at $25 \pm 0.5^{\circ} \mathrm{C}$ with a relative humidity of $75-85 \%$. Ten fruits are collected each 

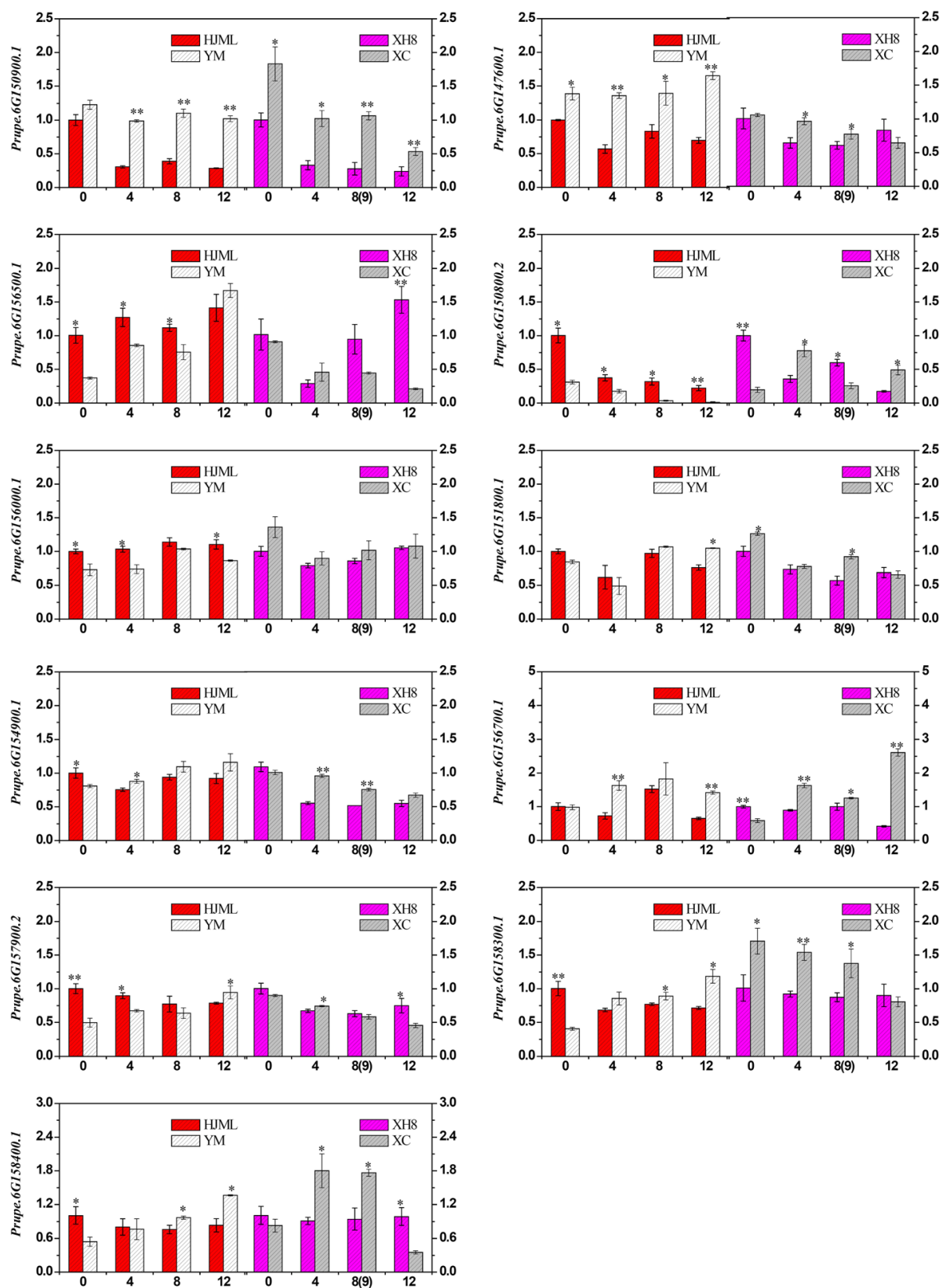

Fig. 7 Relative mRNA expression levels of candidate genes during fruit softening. The $x$-axis represents the storage days after harvest; the $y$-axis represents relative expression levels of genes. Data are means \pm SEs $(n=3)$. Significant differences $(p<0.05)$ between means are indicated by the symbol ${ }^{* \prime}$ and significant differences $(p<0.01)$ between means are indicated by the symbol ${ }^{* * \prime}$

time. Three independent biological replicates were conducted for these measurements.

\section{Determination of the ABA content}

The ABA content was measured using ESI-HPLC-MS/MS (Waters, Milford, USA) as described previously [60]. Briefly, $0.6 \mathrm{~g}$ of peach flesh was homogenized in liquid nitrogen, transferred to a $20-\mathrm{mL}$ centrifuge tube with $5 \mathrm{~mL}$ of isopropanol/hydrochloric acid extraction buffer, and then the reaction solution was vortexed for $30 \mathrm{~min}$ at $4^{\circ}$
C. Subsequently, $10 \mathrm{~mL}$ dichloromethane was added, and the mixture was vortexed at $4{ }^{\circ} \mathrm{C}$ for $30 \mathrm{~min}$. Then, samples were centrifuged at $13000 \mathrm{rpm}$ for $5 \mathrm{~min}$ to separate the organic phase, which was subsequently protected from light and dried under nitrogen gas. It was then re-dissolving dissolved $400 \mu \mathrm{L}$ methanol/methane acid $(99.9 / 0.1, v / \mathrm{v})$. Then, the solution was sequentially passed through a $0.22 \mu \mathrm{m}$ filter membrane to measure with HPLC-MS/MS. The HPLC separation used an ACQUITY UPLC R BEH C18, $100 \mathrm{~mm} \times 2.1 \mathrm{~mm} \times 1.7 \mu \mathrm{m}$ column 
(Waters) and was eluted with $\mathrm{H}_{2} \mathrm{O} /$ methanol $(98 / 2, \mathrm{v} / \mathrm{v})$, $0.05 \%$ methane acid and $5 \mathrm{mmol} / \mathrm{L}$ ammonium acetate (eluent A) and acetonitrile (eluent B) at a flow rate $0.3 \mathrm{~mL} \mathrm{~min}^{-1}$. The temperature of the column was maintained at $40{ }^{\circ} \mathrm{C}$ and the sample size was $5 \mu \mathrm{L}$. The MS methods were as follows: positive, negative ion electrospray ionization, capillary voltage of $3.0 \mathrm{Kv}$, ionization temperature of $150{ }^{\circ} \mathrm{C}$, cone gas flow of $50 \mathrm{~L} / \mathrm{Hr}$, de-solvation temperature of $400{ }^{\circ} \mathrm{C}$, de-solvation gas flow of $800 \mathrm{~L} / \mathrm{Hr}$, monitoring mode of MRM. Comparisons of the peak area ratio (analyte/IS) to concentrations were used to construct the calibration curve, and then the ABA content was calculated based on the calibration curve. Three biological replicates were conducted.

\section{RAD library construction and sequencing}

Illumina DNA sequencing combined with a RAD strategy was used for the effective identification of SNP markers. The RAD-seq library construction protocol was similar to that described in a set of previously published papers [21, 26] . Briefly, $1 \mu \mathrm{g}$ genomic DNA from each individual was digested by the restriction enzyme EcoR1(NEB), and the P1 adapter was added with T4 DNA ligase (NEB) for $1 \mathrm{~h}$ at $37^{\circ} \mathrm{C}$. Ligation products were pooled and fragmented by a Covaris sonicator. Then fragments between 300 and 500 bp were excised after agarose gel electrophoresis selection and purified using a QIAquick Gel Purification Kit (Qiagen). The purified products were combined with End Repair Mix incubated at $20{ }^{\circ} \mathrm{C}$ for $30 \mathrm{~min}$, and then purified again. An end-repaired DNAdA overhang was added by the A-Tailing mix (NEB) at $37^{\circ} \mathrm{C}$ for $30 \mathrm{~min}$. The P2 adapter was added to the product for $15 \mathrm{~min}$ at $20^{\circ} \mathrm{C}$, and the samples were then purified using a QIAquick Gel Purification Kit (Qiagen). PCR amplification was used to enrich the collected fragments, followed by $2 \%$ agarose gel electrophoresis to recover the target fragments. Finally, the library was validated as follows: including: the Agilent 2100 bio analyzer instrument (Agilent DNA 1000 Reagents) was used to determine the average molecule length and RT-qPCR (TaqMan Probe) was used to quantify the libraries. Then, the qualified libraries were amplified on cBot to generate a cluster on the flow cells (PE Cluster Ki,Illumina) and the amplified flow cell were pair-end sequenced in individual lanes of the Illumina HiSeq4000 NGS platform (BGI-Shenzhen, ShenZhen, China).

\section{SNP discovery and genotyping}

After filtering and splitting, Illumina raw sequence reads were retained. Briefly, low-quality data were discarded including: reads with adaptors, reads with more than $50 \%$ bases whose quality values $\leq 5$, and reads that could not be identified with barcode sequences, which are used to classify reads between samples. Clean reads were mapped against the peach genome sequences from the
GDR website (https://www.rosaceae.org/species/prunus_persica/genome_v2.0.a1) with SOAPaligner [61]. Finally, the SNP loci were identified from alignment results using soapsnp software (version 2.23) [62]. Genotypes of offspring individual were based on parental genotypes and markers were tested by chi-squared with the $P$-value set to 0.01 . In addition, the family type was cross pollinators, which is a cross between two heterozygous diploid parents, and its linkage phases were originally unknown [63]. Three segregation types were genotyped, lmxll, nnxnp and hkxhk, with an expected segregation ratio for marker codes lmxll and, nnxnp was being 1:1, and that for lmxll, nnxnp and hkxhk was being 1:2:1. SNP markers with $<10 \%$ missing data in the each individual and consistent with the above standards were used for linkage map construction.

\section{Linkage mapping and QTL analysis}

Construction of the genetic linkage map was accomplished using JoinMap (version 4.1) [63] with 6150 markers and cross pollinators family type. Initially, LGs were constructed using a LOD threshold of 3.0 to 4.0, Kosambi as the mapping function [64], and regression mapping as mapping algorithm. MapChart software (version 2.2) was used to make the map figures [65]. Mean phenotypic data from all 105 individuals (two parents and $103 \mathrm{~F}_{1}$ progeny) are list in Additional file 1. IciMapping software (version 4.1) was used to calculate the QTLs [66] with the ICIM-ADD method. LOD significance thresholds $(P<0.05)$ were analyzed by running 1000 permutation tests.

\section{Candidate gene mining in silico and a functional analysis} Mapping-associated markers were used to identify the homologous regions of QTLs on the physical map. Corresponding genes in QTLs were referred to the peach genome from GDR [42]. To identify the main biological functions of corresponding genes in QTLs, these genes were mapped to each node of the GO database (http:// www.geneontology.org/) [67], and the pathway enrichment was also analyzed in KEGG (http://www.genome.jp/kegg/ pathway.html).

\section{RNA isolation and expression analyses}

The SH cultivars 'YM' and ' $\mathrm{XC}$ ', and $\mathrm{M}$ cultivars 'HJML' and 'XH8' were used to expression analyses. The fruit samples were same as description from Guo et al. [59]. All fruit samples reached commercial maturity, had no diseases and mechanical damage with uniform maturity were randomly collected. And the fruits were stored in a room at at $25 \pm 0.5{ }^{\circ} \mathrm{C}$ with a relative humidity of $75-85 \%$. For HJML, YM and XH8 fruit samples were taken at 0, 4, 8 and $12 \mathrm{~d}$ postharvest; and for XC at $0,4,9$ and $12 \mathrm{~d}$. The pulp from ten fruit were frozen in liquid nitrogen and 
stored at $-80{ }^{\circ} \mathrm{C}$ until further analysis. Three independent biological replicates were conducted for expression analysis. Total RNA was extracted from peach fruit samples using the RNAprep Pure Plant Kit (Polysaccharides \& Polyphenolics-rich) (TIANGEN, Beijing, China), and an ultraviolet spectrophotometer (Eppendorf, Hamburg, Germany) and 1\% agarose gels electrophoresis were used to detect RNA integrity and quality, respectively. cDNA was synthesized using the PrimeScript $^{\mathrm{Tm}}$ RT reagent Kit with gDNA Eraser (TaKaRa, Dalian, China). The NCBI/Primer-BLAST on-line server was used to design specific primers for each gene. All primer sequences are listed in Additional file 8. The translation elongation factor 2 was used as the internal reference gene as in Tong et al. [68]. RT-qPCR was performed on a 7500 Real Time PCR System (Applied Biosystems, NY, USA) with $\mathrm{SYBR}^{\circ}$ Premix Ex $\mathrm{Taq}^{\mathrm{mm}}$ (TaKaRa) and gene-specific primers in a volume of $20 \mu \mathrm{L}$. PCR conditions were as follows: an initial denaturation at $95{ }^{\circ} \mathrm{C}$ for $30 \mathrm{~s}$, and 40 cycles of $95{ }^{\circ} \mathrm{C}$ for $5 \mathrm{~s}$ and $60{ }^{\circ} \mathrm{C}$ for $34 \mathrm{~s}$. The specificity of primer amplifications was checked by a melting curve analysis. The comparative cycle threshold method $(\Delta \Delta \mathrm{Ct})$ was used to analyze relative expression level data [69]. Each sample was analyzed in triplicate.

\section{Statistical analyses}

Microsoft Excel 2010 was used to calculate standard errors (SEs). Graphs were produced using Origin 8.0 software. Significant differences between means of experimental data and a correlation analysis were determined using SPSS 19.0 software (SPSS, Chicago, IL, USA).

\section{Additional files}

Additional file 1: Phenotypic identification of the $103 \mathrm{~F}_{1}$ individuals from a cross between two peach cultivars the SH-type cultivar 'YM' and the M-type cultivar 'HJML'. a. Identification of SH phenotype based on the ethylene production in 2016; b. Identification of SH phenotype based on the fruit firmness in 2017; c. Phenotype identification used for QTL analysis. (DOCX $16 \mathrm{~kb}$ )

Additional file 2: Statistics for the data of RAD-seq in the parent plants and those of their individual offspring. (XLSX $21 \mathrm{~kb}$ )

Additional file 3: 6150 SNP markers identified after filtering used to construct the linkage map in peach. (XLSX $2185 \mathrm{~kb}$ )

Additional file 4: Analysis of the SNP polymorphic sites in the parent plants and their individual offspring in peach. (XLSX $21652 \mathrm{~kb}$ )

Additional file 5: Numbers of SNP transitions types in parent plants and their offspring in peach. (DOCX $21 \mathrm{~kb}$ )

Additional file 6: Discrete genes obtained from QTL regions and the alignment results to GO database and KEGG pathway database. (XLSX $23 \mathrm{~kb}$ )

Additional file 7: Scatter plot illustrating pathway rich factor analysis. (JPG $3748 \mathrm{~kb}$ )
Additional file 8 Specific primers used for RT-qPCR to detect the expression of 11 candidate genes. (DOCX $14 \mathrm{~kb}$ )

\section{Abbreviations}

M: Melting; NM: No-melting; SH: Stony hard; ABA: Abscisic acid; NGS: Nextgeneration sequencing; RAD-seq: Restriction-site associated DNA sequencing; QTL: Quantitative trait loci; LG: Linkage group; SE: Standard error;

GDR: Genome Database for Rosaceae; SNP: Single nucleotide polymorphism; YM: Yumyeoung; HJML: Hu Jing Mi Lu; XH8: Xia Hui 8; XC: Xia Cui; LOD: Likelihood of odd; RT-qPCR: real-time quantitative PCR; GO: Gene Ontology; KEGG: Kyoto Encyclopedia of Genes and Genomes

\section{Acknowledgments}

We acknowledge the critical reading of this manuscript from Dr. Zhijun Shen.

\section{Funding}

This work was financially supported by the earmarked fund for China Agriculture Research System (CARS-30) and grants from Jiangsu Agriculture Science and Technology Innovation Fund (CX (15)1020), Six Talent Fund of Jiangsu Province (No. NY068) and the Priority Academic Program

Development of Jiangsu Higher Education Institutions (PAPD).

\section{Availability of data and materials}

The datasets generated and analyzed during the current study are available in the National Center for Biotechnology Information (NCBI) Sequence Read Archive (SRA) database (http://www.ncbi.nlm.nih.gov/sra/) with the accession number of SRP139715. Additional supporting Tables and Figures are included as Additional files. All plant materials were available from Institute of Pomology, Jiangsu Academy of Agricultural Sciences, P. R. China.

\section{Authors' contributions}

ZG, MY and SG conceived and designed the study, SG and SI phenotyped the plants, prepared the DNA, SG and JS performed the RAD sequencing and bioinformatics analysis, RM made the cross and did data analysis, SG and ZG wrote the paper, and MY, RM, ZG revised the paper. All authors read and approved the final manuscript.

\section{Ethics approval and consent to participate}

Not applicable. No human samples and no animals were used and no field permissions were necessary to collect the plant samples for this study. The authors declared that experimental research works on the plants described in this paper comply with institutional, national and international guidelines.

\section{Competing interests}

The authors declare that they have no competing interests.

\section{Publisher's Note}

Springer Nature remains neutral with regard to jurisdictional claims in published maps and institutional affiliations.

\section{Author details}

${ }^{1}$ College of Horticulture, Nanjing Agricultural University, Nanjing 210095, China. ${ }^{2}$ Institute of Pomology, Jiangsu Academy of Agricultural Sciences, Nanjing 210014, China. ${ }^{3}$ Jiangsu Key Laboratory of Horticultural Crop Genetic Improvement, Nanjing 210014, China.

Received: 17 February 2018 Accepted: 22 July 2018

Published online: 14 August 2018

\section{References}

1. Karabulut OA, Cohen L, Wiess B, Daus A, Lurie S, Droby S. Control of brown rot and blue mold of peach and nectarine by short hot water brushing and yeast antagonists. Postharvest Biol Tec. 2002;24(2):103-11.

2. Yoshioka H, Hayama H, Tatsuki M, Nakamura Y. Cell wall modification during development of mealy texture in the stony-hard peach "Odoroki" treated with propylene. Postharvest Biol Tec. 2010;55(1):1-7.

3. Haji T, Yaegaki H, Yamaguchi M. Changes in ethylene production and flesh firmness of melting, nonmelting and stony hard peaches after harvest. Engei Gakkai Zasshi. 2001;70(4):458-9. 
4. Haji T, Yaegaki H, Yamaguchi M. Inheritance and expression of fruit texture melting, non-melting and stony hard in peach. Sci Hortic-amsterdam. 2005; 105(2):241-8.

5. Yoshida M. Genetic studies on the fruit quality of peach varieties III texture and keeping quality. Bull Fruit Tree Res Station. 1976;3:1-16

6. Pan L, Zeng W, Niu L, Lu Z, Liu H, Cui G, Zhu Y, Chu J, Li W, Fang W, et al. PpYUC11, a strong candidate gene for the stony hard phenotype in peach (Prunus persica L. Batsch), participates in IAA biosynthesis during fruit ripening. J Exp Bot. 2015;66(22):7031-44

7. Biale J, Young R. Respiration and ripening in fruits - retrospect and prospect. In: Friend J, Rhodes MJC (eds). Recent advances in the Biochemistry of fruit and vegetables. London: Academic Press; 1981. p. 1-39.

8. Callahan AM, Scorza R, Bassett C, Nickerson M, Abeles FB. Deletions in an endopolygalacturonase gene cluster correlate with non-melting flesh texture in peach. Funct Plant Biol. 2004;31(2):159-68.

9. Pressey R, Avants JK. Separation and characterization of Endopolygalacturonase and Exopolygalacturonase from peaches. Plant Physiol. 1973;52(3):252

10. Tatsuki M. The involvement of 1-aminocyclopropane-1-carboxylic acid synthase isogene, Pp-ACS1, in peach fruit softening. J Exp Bot. 2006;57(6):1281-9.

11. Tatsuki M, Nakajima N, Fujii H, Shimada T, Nakano M, Hayashi K, Hayama H, Yoshioka H, Nakamura Y. Increased levels of IAA are required for system 2 ethylene synthesis causing fruit softening in peach (Prunus persica L. Batsch). J Exp Bot. 2013;64(4):1049.

12. Dong Z, Yu Y, Li S, Wang J, Tang S. Abscisic acid antagonizes ethylene production through the ABI4-mediated transcriptional repression of ACS4 and ACS8 in Arabidopsis. Mol Plant. 2016;9(1):126-35.

13. Li Z, Zhang L, Yu Y, Quan R, Zhang Z, Zhang H, Huang R. The ethylene response factor AtERF11 that is transcriptionally modulated by the bZIP transcription factor HY5 is a crucial repressor for ethylene biosynthesis in Arabidopsis. Plant J. 2011;68(1):88-99.

14. Peterson BK, Weber JN, Kay EH, Fisher HS, Hoekstra HE. Double digest RADseq: an inexpensive method for De novo SNP discovery and genotyping in model and non-model species. PLoS One. 2012;7(5):e37135.

15. Pan L, Wang N, Wu Z, Guo R, Yu X, Zheng Y, Xia Q, Gui S, Chen C. A high density genetic map derived from RAD sequencing and its application in QTL analysis of yield-related traits in Vigna unguiculata. Front Plant Sci. 2017;8:1544.

16. Wang N, Fang L, Xin H, Wang L, Li S. Construction of a high-density genetic map for grape using next generation restriction-site associated DNA sequencing. BMC Plant Biol. 2012;12(1):148.

17. Wu K, Liu H, Yang M, Ye T, Ma H, Wu W, Yang Z, Zhao Y. High-density genetic map construction and QTLs analysis of grain yield-related traits in sesame (Sesamum indicum L.) based on RAD-Seq techonology. BMC Plant Biol. 2014;14(1):1-14

18. Barchi L, Lanteri S, Portis E, Volante A, Pulcini L, Ciriaci T, Acciarri N, Barbierato V, Toppino L, Rotino GL. A RAD tag derived marker based eggplant linkage map and the location of QTLs determining anthocyanin pigmentation. PLoS One. 2012;7(8):e43740.

19. Pfender WF, Saha MC, Johnson EA, Slabaugh MB. Mapping with RAD (restriction-site associated DNA) markers to rapidly identify QTL for stem rust resistance in Lolium perenne. Theor Appl Genet. 2011;122(8):1467-80.

20. Chutimanitsakun Y, Nipper RW, Cuestamarcos A, Cistué L, Corey A, Filichkina $T$, Johnson EA, Hayes PM. Construction and application for QTL analysis of a restriction site associated DNA (RAD) linkage map in barley. BMC Genomics. 2011;12(1):4

21. Wu J, Li LT, Li M, Khan MA, Li XG, Chen H, Yin H, Zhang SL. High-density genetic linkage map construction and identification of fruit-related QTLS in pear using SNP and SSR markers. J Exp Bot. 2014;65(20):5771-81.

22. Sun R, Chang Y, Yang F, Wang Y, Li H, Zhao Y, Chen D, Wu T, Zhang X, Han Z. A dense SNP genetic map constructed using restriction site-associated DNA sequencing enables detection of QTLs controlling apple fruit quality. BMC Genomics. 2015;16(1):747.

23. Chapman MA, Pashley CH, Wenzler J, Hvala J, Tang S, Knapp SJ, Burke JM. A genomic scan for selection reveals candidates for genes involved in the evolution of cultivated sunflower (Helianthus annuus). Plant Cell. 2008;20(11):2931.

24. Haji T. Inheritance of flesh texture in peach and effects of ethylene treatment on softening of the stony hard peach. Jarq-Jpn Agr Res Q. 2014 48(1):57-61.

25. Zhou X, Xia Y, Ren X, Chen Y, Li H, Huang S, Liao B, Lei $Y$, Yan L, Jiang H. Construction of a SNP-based genetic linkage map in cultivated peanut based on large scale marker development using next-generation doubledigest restriction-site-associated DNA sequencing (ddRADseq). BMC Genomics. 2014;15(1):351.

26. Baird NA, Etter PD, Atwood TS, Currey MC, Shiver AL, Lewis ZA, Selker EU, Cresko WA, Johnson EA. Rapid SNP discovery and genetic mapping using sequenced RAD markers. PLoS One. 2008;3(10):e3376.

27. Davey JW, Blaxter ML. RADSeq: next-generation population genetics. Brief Funct Genomics. 2010;9(5-6):416-23.

28. Raman H, Raman R, Coombes N, Song J, Prangnell R, Bandaranayake C, Tahira R, Sundaramoorthi V, Killian A, Meng J. Genome-wide association analyses reveal complex genetic architecture underlying natural variation for flowering time in canola. Plant Cell Environ. 2016;39(6):1228-39.

29. Zou J, Hu D, Liu P, Raman H, Liu Z, Liu X, Parkin IAP, Chalhoub B, Meng J. Co-linearity and divergence of the a subgenome of Brassica juncea compared with other Brassica species carrying different a subgenomes. BMC Genomics. 2016;17(1):1-14.

30. Chaparro JX, Werner DJ, O'Malley D, Sederoff RR. Targeted mapping and linkage analysis of morphological isozyme, and RAPD markers in peach. Theor Appl Genet. 1994;87(7):805-15.

31. Blenda AV, Verde I, Georgi LL, Reighard GL, Forrest SD, Muñoz-Torres M, Baird WV Abbott AG. Construction of a genetic linkage map and identification of molecular markers in peach rootstocks for response to peach tree short life syndrome. Tree Genet Genomes. 2007;3(4):341-50.

32. Dirlewanger E, Cosson P, Boudehri K, Renaud C, Capdeville G, Tauzin Y, Laigret F, Moing A. Development of a second-generation genetic linkage map for peach [Prunus persica (L.) Batsch] and characterization of morphological traits affecting flower and fruit. Tree Genet Genomes. 2006;3(1):1-13.

33. Dirlewanger E, Pronier V, Parvery C, Rothan C, Guye A, Monet R. Genetic linkage map of peach [Prunus persica (L.) Batsch] using morphological and molecular markers. Theor Appl Genet. 1998;97(5-6):888-95.

34. Rajapakse S, Belthoff LE, He G, Estager AE, Scorza R, Verde I, Ballard RE, Baird W, Callahan A, Monet R. Genetic linkage mapping in peach using morphological, RFLP and RAPD markers. Theor Appl Genet. 1995;90(3-4):503.

35. Shen Z, Confolent C, Lambert P, Poëssel JL, Quilot-Turion B, Yu M, Ma R Pascal T. Characterization and genetic mapping of a new blood-flesh trait controlled by the single dominant locus DBF in peach. Tree Genet Genomes. 2013;9(6):1435-46.

36. Yamamoto $T$, Shimada $T$, Imai $T$, Yaegaki $H$, Haji T, Matsuta $N$, Yamaguchi $M$, Hayashi T. Characterization of morphological traits based on a genetic linkage map in peach. Jpn J Breed. 2001;51(4):271-8.

37. Slate J, Gratten J, Beraldi D, Stapley J, Hale M, Pemberton JM. Gene mapping in the wild with SNPs: quidelines and future directions. Genetica. 2009;136(1):97.

38. Joobeur T, Viruel MA, Vicente MCD, Jáuregui B, Ballester J, Dettori MT, Verde I, Truco MJ, Messeguer R, Batlle I. Construction of a saturated linkage map for Prunus using an almondxpeach F2 progeny. Theor Appl Genet. 1998;97(7):1034-41.

39. Martínez-García PJ, Dan EP, Ogundiwin EA, Fass J, Chan HM, Ahmad R, Lurie S, Dandekar A, Gradziel TM, Crisosto CH. High density SNP mapping and QTL analysis for fruit quality characteristics in peach (Prunus persica L.). Tree Genet Genomes. 2013;9(1):19-36.

40. Wu J, Shu H, Zhang K, Jiang L, Zhou X, Xin C. Construction and analysis of peach genetic map. Acta Horticulturae Sinica. 2004;31(5):593-7.

41. Zeballos JL, Abidi W, Giménez R, Monforte AJ, Moreno MÁ, Gogorcena Y. Mapping QTLs associated with fruit quality traits in peach [Prunus persica (L.) Batsch] using SNP maps. Tree Genet Genomes. 2016;12(3):37.

42. Verde I, Abbott AG, Scalabrin S, Jung S, Shu S, Marroni F, Zhebentyayeva T, Dettori MT, Grimwood J, Cattonaro F. The high-quality draft genome of peach (Prunus persica) identifies unique patterns of genetic diversity, domestication and genome evolution. Nat Genet. 2013;45(5):487.

43. Ogundiwin EA, Peace CP, Gradziel TM, Dan EP, Bliss FA, Crisosto CH. A fruit quality gene map of Prunus. BMC Genomics. 2009;10(1):587.

44. Abbott A, Georgi L, Yvergniaux D, Wang Y, Blenda A, Reighard G, Inigo M, Sosinski B. Peach: the model genome for Rosaceae. Acta Hortic. 2002;575(1):145-56.

45. Eduardo I, Chietera G, Pirona R, Pacheco I, Troggio M, Banchi E, Bassi D, Rossini $L$, Vecchietti A, Pozzi C. Genetic dissection of aroma volatile compounds from the essential oil of peach fruit: QTL analysis and identification of candidate genes using dense SNP maps. Tree Genet Genomes. 2013;9(1):189-204.

46. Illa E, Eduardo I, Audergon JM, Barale F, Dirlewanger E, Li X, Moing A, Lambert P, Le DL, Gao Z. Saturating the Prunus (stone fruits) genome with candidate genes for fruit quality. Mol Breed. 2011;28(4):667-82.

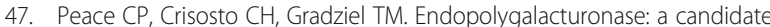
gene for freestone and melting Fleshin peach. Mol Breed. 2005;16(1):21-31. 
48. Lester DR, Sherman WB, Atwell BJ. Endopolygalacturonase and the melting flesh (M) locus in peach. J Am Soc Hortic Sci. 1996;121(2):231-5.

49. Serra O, Giné-Bordonaba J, Eduardo I, Bonany J, Echeverria G, Larrigaudière C, Arús P. Genetic analysis of the slow-melting flesh character in peach. Tree Genet Genomes. 2017;13(4):77.

50. Frett TJ, Reighard GL, Okie WR, Gasic K. Mapping quantitative trait loci associated with blush in peach [Prunus persica (L.) Batsch]. Tree Genet Genomes. 2014;10(2):367-81.

51. Beaudoin N, Serizet C, Gosti F, Giraudat J. Interactions between Abscisic acid and ethylene signaling cascades. Plant Cell. 2000;12(7):1103-15.

52. Ghassemian M, Nambara E, Cutler S, Kawaide H, Kamiya Y, Mccourt P. Regulation of Abscisic acid signaling by the ethylene response pathway in Arabidopsis. Plant Cell. 2000;12(7):1117-26.

53. Luo X, Chen Z, Gao J, Gong Z. Abscisic acid inhibits root growth in Arabidopsis through ethylene biosynthesis. Plant J. 2014;79(1):44-55.

54. Koiwai H, Nakaminami K, Seo M, Mitsuhashi W, Toyomasu T, Koshiba T. Tissue-specific localization of an abscisic acid biosynthetic enzyme, AAO3, in Arabidopsis. Plant Physiol. 2004;134(4):1697-707.

55. Woeste KE, Ye C, Kieber JJ. Two Arabidopsis mutants that overproduce ethylene are affected in the posttranscriptional regulation of 1-Aminocyclopropane-1carboxylic acid synthase. Plant Physiol. 1999;119(2):521-9.

56. Wright STC. The effect of plant growth regulator treatments on the levels of ethylene emanating from excised turgid and wilted wheat leaves. Planta. 1980;148(4):381-8.

57. Hayama H, Shimada T, Fujii H, Ito A, Kashimura Y. Ethylene-regulation of fruit softening and softening-related genes in peach. J Exp Bot. 2006;57(15):4071-7.

58. Hayama $\mathrm{H}$, Tatsuki M, Ito A, Kashimura Y. Ethylene and fruit softening in the stony hard mutation in peach. Postharvest Biol Tec. 2006;41(1):16-21.

59. Guo S, Song J, Zhang B, Jiang H, Ma R, Yu M. Genome-wide identification and expression analysis of beta-galactosidase family members during fruit softening of peach [Prunus persica (L.) Batsch]. Postharvest Biol Tec. 2018; 136(Supplement C):111-23.

60. Yin X, He D, Ravi G, Yang P. Physiological and proteomic analyses on artificially aged Brassica napusseed. Front Plant Sci. 2015;6(112):112.

61. Li R, Yu C, Li Y, Lam TW, Yiu SM, Kristiansen K, Wang J. SOAP2: an improved ultrafast tool for short read alignment. Bioinformatics. 1966;25(15):1966-7.

62. Li R, Li Y, Fang X, Yang H, Wang J, Kristiansen K, Wang J. SNP detection for massively parallel whole-genome resequencing. Genome Res. 2009;19(6):1124.

63. Van Ooijen JW. JoinMap 4. Wageningen: Softw Calc Genet Link maps Exp Popul Kyazma BV; 2006.

64. Kosambi DD. The estimation of map distance from recombination values. Ann Hum Genet. 1943;12(1):172-5.

65. Voorrips RE. MapChart: software for the graphical presentation of linkage maps and QTLs. J Hered. 2002;93(1):77-8.

66. Wang J, Li H, Zhang L, Meng L. Users' manual of QTL IciMapping version 3. 2. Quant Genet Group, Inst Crop Sci Chinese Acad Agric Sci (CAAS), Beijing 2012, 100081. http://www.sciencedirect.com/science/article/pii/ S2214514115000161.

67. Harris MA, Clark J, Ireland A, Lomax J, Ashburner M, Foulger R, Eilbeck K, Lewis S, Marshall B, Mungall C, Richter J, Rubin GM, Blake JA, Bult C, Dolan M, Drabkin H, Eppig JT, Hill DP, Ni L, Ringwald M, Balakrishnan R, Cherry JM, Christie KR, Costanzo MC, Dwight SS, Engel S, Fisk DG, Hirschman JE, Hong EL, Nash RS, Sethuraman A, Theesfeld CL, Botstein D, Dolinski K, Feierbach B, Berardini T, Mundodi S, Rhee SY, Apweiler R, Barrell D, Camon E, Dimmer E, Lee V, Chisholm R, Gaudet P, Kibbe W, Kishore R, Schwarz EM, Sternberg P, Gwinn M, Hannick L, Wortman J, Berriman M, Wood V, de la CN, Tonellato $P$, Jaiswal P, Seigfried T, White R. The gene ontology (GO) database and informatics resource. Nucleic Acids Res. 2004;32:D258-D261. https://doi.org/ 10.1093/nar/gkh066

68. Tong ZG, Gao ZH, Wang F, Zhou J, Zhang Z. Selection of reliable reference genes for gene expression studies in peach using real-time PCR. BMC Mol Biol. 2009;10(1):1-13.

69. Livak KJ, Schmittgen TD. Analysis of relative gene expression data using real-time quantitative PCR and the 2(-Delta Delta C(T)) method. Methods. 2001;25(4):402-8.

Ready to submit your research? Choose BMC and benefit from:
- fast, convenient online submission
- thorough peer review by experienced researchers in your field
- rapid publication on acceptance
- support for research data, including large and complex data types
- gold Open Access which fosters wider collaboration and increased citations
- maximum visibility for your research: over 100M website views per year
At BMC, research is always in progress.
Learn more biomedcentral.com/submissions

